\title{
The activity of micafungin against clinical isolates of non-albicans Candida spp.
}

\author{
Anna Biernasiuk ${ }^{1 *}$, Ewelina Dobiecka ${ }^{1}$, Grazyna Zdzienicka $^{2}$, Anna Malm $^{1}$
}

${ }^{1}$ Department of Pharmaceutical Microbiology, Medical University of Lublin, Chodzki 1, 20-093 Lublin, Poland
${ }^{2}$ Department of Diagnostics Microbiology, Independent Public Teaching Hospital No 1, Staszica 16, 20-081 Lublin, Poland

\section{ARTICLE INFO}

Received 02 March 2015

Accepted 12 March 2015

\section{Keywords:}

micafungin

non-albicans Candida spp.,

E-test,

minimal inhibitory

concentration (MIC).

\begin{abstract}
Infections caused by non-albicans Candida spp. are an important medical problem in people from risk groups, e.g. hematooncological patients. The aim of this paper was to analyse the in vitro activity of micafungin against 30 clinical isolates of non-albicans Candida spp. (C. glabrata, C. famata, C. tropicalis, C. inconspicua, C. lusitaniae, C. parapsilosis, C. krusei) by way of the E-test procedure, allowing determination of minimal inhibitory concentration (MIC). Data presented in this paper indicate that most of the studied clinical isolates - $27(90 \%)$ showed sensitivity to micafungin, with MIC values ranging from 0.004 to $2 \mathrm{mg} / \mathrm{l}$, while $3(10 \%)$ isolates, including 2 isolates of $C$. tropicalis and 1 isolate of $C$. famata, were resistant to micafungin, with MIC values $>32 \mathrm{mg} / \mathrm{l}$. The $\mathrm{MIC}_{50}$ and $\mathrm{MIC}_{90}$ values of micafungin, defined as MIC inhibited growth of $50 \%$ or $90 \%$ of the isolates studied, were $0.008 \mathrm{mg} / \mathrm{l}$ or $2 \mathrm{mg} / \mathrm{l}$, respectively. In the case of C. glabrata isolates, MICs ranged from 0.004 to $0.016 \mathrm{mg} / \mathrm{l}$, while $\mathrm{MIC}_{50}$ was $0.004 \mathrm{mg} / \mathrm{l}$ and $\mathrm{MIC}_{90}$ $-0.008 \mathrm{mg} / \mathrm{l}$. Our data confirm the utility of micafungin for the therapy of the infections caused by non-albicans Candida spp., especially C. glabrata.
\end{abstract}

\section{INTRODUCTION}

Invasive fungal infections induced by Candida spp. are a significant cause of morbidity and mortality worldwide. Moreover, changes in the spectrum of Candida spp. responsible for candidiases have been observed in recent years. Currently, the major pathogen is still C. albicans (more than $75 \%$ of infections), while the incidence of non-albicans Candida spp. infections is steadily increasing. Indeed, the prevalence of $C$. glabrata infections has increased from 2 to $26 \%$, that of $C$. tropicalis - from 2 to $24 \%$ and that of C. parapsilosis - from 9 to $20 \%[2,13,14]$, especially in patients from several risk groups. These groups of patients include those undergoing surgical procedures, those with intravenous drug administration, organ transplant recipients, oncology patients and individuals with some endocrynological disorders (e.g. diabetes mellitus) $[2,13,14]$.

Micafungin belongs to a unique class of new antifungals known as the 'echinocandins'. Its antifungal mechanism is based on the inhibition of $1,3-\beta$-D-glucan biosynthesis, an essential polysaccharide that is a main structural component of the fungal cell wall, which in turn, is

* Corresponding author
e-mail: ania.biernasiuk@umlub.pl
tel./fax: 81 448-71-00

responsible for structural cell integrity and osmotic stability $[1,4,7,10,12,35,36]$. At the moment, micafungin is the firstline treatment for invasive and deep-seated Candida spp. infections and has excellent antifungal effects in vitro against the yeast strains resistant to amphotericin B and azoles, especially to $C$. glabrata (which is intrinsically resistant to fluconazole) $[6,16,18,20]$. Micafungin is also recommended in treating candidiasis ranging from superficial infections, such as oral thrush and vaginitis, to systemic and potentially life-threatening diseases, e.g. esophageal candidiasis or candidemia $[8,9,15,19,21]$. However, there is a need to monitor the sensitivity of Candida spp. clinical isolates to echinocandins, including micafungin, in order to assess the rate of resistance to these drugs. The aim of this paper was to analyse the in vitro activity of micafungin by the E-test procedure, against 30 clinical isolates of non-albicans Candida spp. derived from different clinical specimens obtained from hospitalized patients, especially hematooncological persons.

\section{MATERIAL AND METHODS}

The study protocol (No. KE-0254/75/2011) was approved by the Ethical Committee of the Medical University of Lublin. In it, clinical specimens (e.g. blood, spit, urine, 
feces and swabs from oral cavity, throat and nose, ear, vagina or cervix) were obtained from hospitalized patients, especially hematooncological patients. The specimens were immediately streaked onto CHROMagar Candida Medium (Becton Dickinson). The studied 30 clinical isolates of nonalbicans Candida spp. included: C. glabrata, C. famata, $C$. tropicalis, C. inconspicua, C. lusitaniae, C. parapsilosis, C. krusei (Table 1). The isolates were identified by biochemical microtest API 20 C AUX (bioMerieux), on the basis of assimilation of various substrates.

Table 1. Species distribution among clinical isolates of nonalbicans Candida spp. used in the present study

\begin{tabular}{|c|c|}
\hline Species & $\begin{array}{c}\text { Number (percentage) of isolates } \\
(\mathrm{n}=30)\end{array}$ \\
\hline C. glabrata & 15 \\
\hline C. famata & 6 \\
\hline C. tropicalis & 3 \\
\hline C. inconspicua & 2 \\
\hline C. lusitaniae & 2 \\
\hline C. parapsilosis & 1 \\
\hline C. krusei & 1 \\
\hline
\end{tabular}

Micafungin susceptibility was assessed by the E-test procedure (AB BIODISK), using RPMI 1640 medium (SIGMA-ALDRICH) buffered to a $\mathrm{pH} 7.0$ with 0.165 morpholine propanesulphonic acid (MOPS). The E-test is a quantitative technique for determining the minimum inhibitory concentration (MIC) of antimicrobial agents. MIC is defined as the lowest concentration of antimicrobial agent that will inhibit the visible growth of microorganisms. Inocula were prepared using European Committee for Antimicrobial Susceptibility Testing (EUCAST) guidelines [3]. The plates were incubated at $35^{\circ} \mathrm{C}$ and the MIC values were determined after 48 hours of incubation. Using standard E-test procedure, MIC was read directly from the scale in terms of $\mathrm{mg} / \mathrm{l}$ at the point where the edge of the ellipse inhibition zone intersects the strip (Figure 1). The MIC of micafungin for the reference yeast strain $C$. parapsilosis ATCC 22019 was $1.5 \mathrm{mg} / 1$, i.e. within the recommended $\mathrm{MIC}$ range $0.25-2 \mathrm{mg} / \mathrm{l}$.

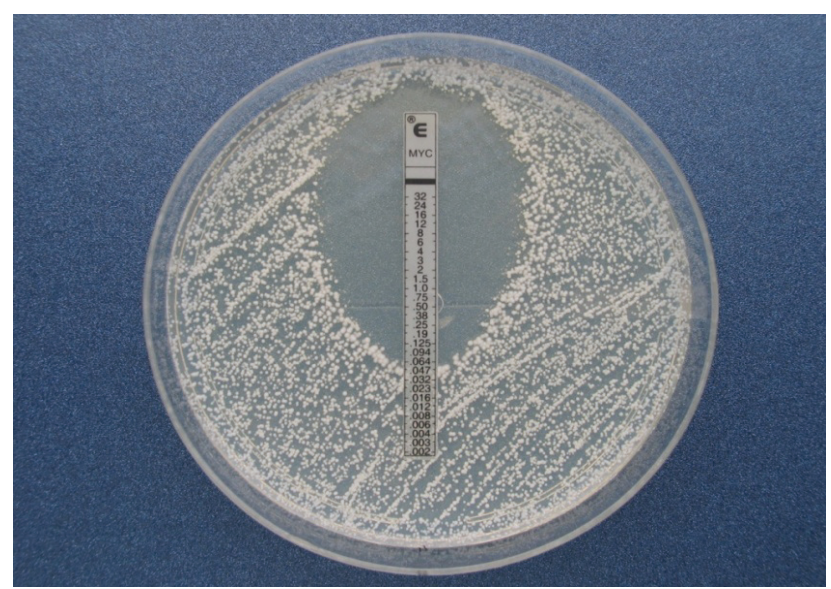

Figure 1. Determination of MIC of micafungin by E-test for the isolate of non-albicans Candida spp.

\section{RESULTS}

As shown in Table 2, most of the studied clinical isolates of non-albicans Candida spp. - 27 (90\%) showed sensitivity to micafungin, with MIC values ranging from 0.004 to $2 \mathrm{mg} / \mathrm{l}$, while $3(10 \%)$ isolates, including 2 isolates of C. tropicalis and 1 isolate of C. famata were resistant to micafungin - with MIC values $>32 \mathrm{mg} / \mathrm{l}$. As presented in Table 3, the $\mathrm{MIC}_{50}$ and $\mathrm{MIC}_{90}$ values of micafungin, defined as the MIC which inhibited growth of $50 \%$ or $90 \%$ of the isolates, were $0.008 \mathrm{mg} / \mathrm{l}$ or $2 \mathrm{mg} / \mathrm{l}$, respectively. In the case of the $C$. glabrata isolates, representing $50 \%$ of the isolates studied, MICs ranged from 0.004 to $0.008 \mathrm{mg} / 1$, with $\mathrm{MIC}_{50}$ at $0.004 \mathrm{mg} / \mathrm{l}$, and $\mathrm{MIC}_{90}$ at $0.008 \mathrm{mg} / \mathrm{l}$.

Table 2. The sensitivity of clinical isolates of non-albicans Candida spp. to micafungin

\begin{tabular}{|c|c|c|}
\hline $\begin{array}{c}\text { MIC of } \\
\text { micafungin } \\
(\mathrm{mg} / \mathrm{l})\end{array}$ & $\begin{array}{c}\text { Number (percentage) of non- } \\
\text { albicans Candida spp. isolates } \\
(\mathrm{n}=30)\end{array}$ & $\begin{array}{c}\text { Number (percentage) of } \\
\text { Candida glabrata isolates } \\
(\mathrm{n}=15)\end{array}$ \\
\hline 0.004 & $5(16.67)$ & $5(33.33)$ \\
\hline 0.008 & $10(33.33)$ & $8(53.33)$ \\
\hline 0.016 & $4(13.33)$ & $2(13.33)$ \\
\hline 0.032 & $3(11.11)$ & 0 \\
\hline 0.064 & $3(11.11)$ & 0 \\
\hline 0.125 & $1(3.33)$ & 0 \\
\hline 2 & $1(3.33)$ & 0 \\
\hline$>32$ & $3(10)$ & 0 \\
\hline
\end{tabular}

Table 3. The $\mathrm{MIC}_{50}$ and $\mathrm{MIC}_{90}$ of micafungin for clinical isolates of non-albicans Candida spp.

\begin{tabular}{|c|c|c|}
\hline MIC (mg/l) & non-albicans Candida spp. & Candida glabrata \\
\hline MIC $_{50}$ & 0.008 & 0.004 \\
\hline MIC $_{90}$ & 2 & 0.008 \\
\hline
\end{tabular}

\section{DISCUSSION}

The increased frequency of fungal infections in recent years is associated with several factors, including inappropriate use of antifungal drugs. Our data indicate that most of the studied clinical isolates of non-albicans Candida spp. (C. glabrata, C. famata, C. tropicalis, C. inconspicua, C. lusitaniae, C. parapsilosis, C. krusei) obtained from hospitalized patients showed sensitivity to micafungin, with a MIC range of 0.004 to $2 \mathrm{mg} / \mathrm{l}$. These data are in accord with the results presented by other authors, wherein micafungin showed good activity in vitro against a broad range of Candida spp. As reported by Nguyen et al. [23], MIC of micafungin ranged from 0.008 to $0.125 \mathrm{mg} / 1$ for $C$. glabrata and C. krusei, and from 0.5 to $1 \mathrm{mg} / 1$ for $C$. parapsilosis. Pfaller et al. [26] found that micafungin was very active against non-albicans Candida spp. (C. glabrata, C. tropicalis, C. kefyr, C. krusei, C. lusitaniae, C. guilliermondii, C. parapsilosis) isolated from different clinical specimens from patients in 100 medical centers, in the years $2003-2007$, with MIC ranging from 0.015 to $1 \mathrm{mg} / \mathrm{l}$. Similar data were reported by other authors [11,17,22,25,32,33], who reveal that micafungin was active against clinical isolates of $C$. tropicalis, C. glabrata, C. parapsilosis, C. dubliniensis and 
C. krusei, with a MIC range from 0.002 to $1 \mathrm{mg} / \mathrm{l}$. Of note, higher MIC values of micafungin ( $\geq 2 \mathrm{mg} / \mathrm{l}$ ) were usually evidenced for $C$. tropicalis and C. parapsilosis [17,32,33].

There has been a gradual increase in the incidence of C. glabrata related nosocomial infections. The treating of these infections can be difficult because this species may be resistant to fluconazole. Micafungin, a newer antifungal agent, provides an alternative and effective therapy against C. glabrata infections, especially that caused by the isolates which had developed resistance to fluconazole $[6,20]$. Indeed, C. glabrata is naturally about 8-fold more insensitive to fluconazole than $C$. albicans. A study performed in the US showed the very high efficiency of micafungin in treating $C$. glabrata infections caused by the isolates resistant to fluconazole, and which were obtained from patients with candidiases of the oral cavity and throat [20]. The data presented in this paper showed that clinical isolates of $C$. glabrata were highly susceptible to micafungin, with MIC ranging from 0.004 to $0.016 \mathrm{mg} / 1$.

Echinocandins are a relatively new group of antifungals, and, currently, resistance to them is rare $[30,31,38]$. Our data indicate that only $10 \%$ of clinical isolates of non-albicans Candida spp. (C. tropicalis, C. famata) were resistant to micafungin, with MIC $\geq 32 \mathrm{mg} / \mathrm{l}$. It should be noted that breakpoint for micafungin-resistant strains is $>2 \mathrm{mg} / \mathrm{l}$ [3]. As found by Pfeiffer et al. [30], MIC of micafungin for only a few clinical strains of non-albicans Candida spp., e.g. C. tropicalis and C. parapsilosis were higher than $2 \mathrm{mg} / \mathrm{l}$, indicating insensitivity of the isolates. What is more, other authors found that some isolates of C. glabrata, C. tropicalis and $C$. parapsilosis obtained from different clinical materials in patients suffering from candidiases, showed MIC above 2 $\mathrm{mg} / \mathrm{l}$, this figure deciding about their resistance to this agent.

The $\mathrm{MIC}_{50}$ and $\mathrm{MIC}_{90}$ of micafungin for non-albicans Candida spp. isolates, obtained in the present study were $0.008 \mathrm{mg} / 1$ and $2 \mathrm{mg} / \mathrm{l}$, respectively. Similar data were reported by Pfaller et al. [27-29]. These authors revealed that $\mathrm{MIC}_{50}$ and $\mathrm{MIC}_{90}$ of micafungin for Candida spp. (C. albicans, C. glabrata, C. tropicalis, C. parapsilosis, C. krusei and C. guilliermondii) isolated from different clinical centers in 2001-2006, were $0.015-1 \mathrm{mg} / 1$ and $0.015-2$ $\mathrm{mg} / \mathrm{l}$, respectively. Furthermore, according to other authors $[11,20], \mathrm{MIC}_{50}$ of micafungin for non-albicans Candida spp. (C. glabrata, C. tropicalis, C. parapsilosis, C. krusei, C. lusitaniae and $C$. guilliermondii) ranged from 0.015 to 0.5 $\mathrm{mg} / \mathrm{l}$, while $\mathrm{MIC}_{90}$ ranged from 0.015 to $1 \mathrm{mg} / \mathrm{l}$.

As reported in this paper, the $\mathrm{MIC}_{50}$ of micafungin for $C$. glabrata isolates was $0.004 \mathrm{mg} / 1$ and $\mathrm{MIC}_{90}-0.008 \mathrm{mg} / \mathrm{l}$. According to the data obtained by Pfaller et al. [27,28,29], $\mathrm{MIC}_{50}$ and $\mathrm{MIC}_{90}$ of micafungin were $0.015 \mathrm{mg} / 1$ for $C$. glabrata isolates from different clinical materials obtained from several medical centers.

The presented data, showing the high in vitro activity of micafungin against non-albicans Candida spp. clinical isolates (including C. glabrata), along-side those from literature $[5,24,34,37]$ concerning the in vitro data, as well as data derived from clinical trials, point to the clinical significance of micafungin as an alternative option in the therapy of candidiases, especially invasive ones.

\section{CONCLUSION}

The data presented in this paper demonstrate that most of the studied clinical isolates of non-albicans Candida spp. showed sensitivity in vitro to micafungin. These data confirm the utility of micafungin for the therapy of the infections caused by non-albicans Candida spp., especially $C$. glabrata.

\section{REFERENCES}

1. Abuhammour W., Habte-Gaber E.: Newer antifungal agents. Indian. J. Pediatr., 71, 253, 2004.

2. Andes D.R. et al.: In vivo pharmacodynamic target investigation for micafungin against Candida albicans and C. glabrata in a neutropenic murine candidiasis model. Antimicrob. Agents Chemother., 52, 3497, 2008.

3. Arendrup M.C. et al.: European Committee for Antimicrobial Susceptibility Testing (EUCAST). Methods for the determination of broth dilution minimum inhibitory concentrations of antifungal agents for yeasts. EUCAST definitive document EDef 7.2 Revision. March 2012.

4. Baran E., Dyląg M.: Echinokandyny - wielkocząsteczkowe lipopeptydy o aktywności przeciwgrzybiczej. Przegl. Dermatol., 93, 131, 2006.

5. Barry A.L. et al.: Quality control limits for broth microdilution susceptibility tests of ten antifungal agents. J. Clin. Microbiol., 38, 3457, 2000.

6. Bennett J.E., Izumikawa K., Marr K.A.: Mechanism of increased fluconazole resistance in Candida glabrata during prophylaxis. Antimicrob. Agents Chemother., 48, 1773, 2004.

7. Bormann A.M., Morrison V.A.: Review of the pharmacology and clinical studies of micafungin. Drug Des. Devel. Ther., 29, 295, 2009.

8. Carter N.J., Keating G.M.: Micafungin: A review of its use in the prophylaxis and treatment of invasive Candida infections in pediatric patients. Paediatr Drugs., 11, 271, 2009.

9. Chandrasekar P.H., Sobel J.D.: Micafungin: A new echinocandin. Clin. Infect. Dis., 42, 1171, 2006.

10. Chion Ch., Groll A., Walsh T.: New drugs and novel targets for treatment of invasive fungal infections. Oncologist., 2, 120, 2000.

11. Choi H.W. et al.: In vitro susceptibilities to caspofungin and micafungin of clinical isolates of Candida species. Korean J. Lab. Med., 26, 275, 2006.

12. Dzierżanowska D.: Nowe antybiotyki stosowane w terapii inwazyjnych zakażeń grzybiczych. Zakażenia, 8, 34, 2008.

13. Dzierżanowska D. (2007). Patogeny zakażeń szpitalnych. BielskoBiała: $\alpha$-medicapress.

14. Dzierżanowska D. (2007). Postacie kliniczne zakażeń szpitalnych. Bielsko-Biała: $\alpha$-medicapress.

15. Eschenauer G., de Pestel D.D., Carver P.L.: Comparison of echinocandin antifungals. Ther. Clin. Risk. Manag., 3, 71, 2007.

16. Hashimoto S.: Micafungin: A sulfated echinocandin. J. Antibiot., $62,27,2009$

17. Ikeda F. et al.: Antifungal activity of micafungin against Candida and Aspergillus spp. isolated from pediatric patients in Japan. Med. Mycol., 47, 145, 2009.

18. Joseph J.M., Jain R., Danziger L.H.: Micafungin: A new echinocandin antifungal. Pharmacother., 27, 53, 2007.

19. Karthaus M., Cornely O.A.: Treatment options in candidaemia. Mycoses, 50, 44, 2007.

20. Messer S.A. et al.: Activities of micafungin against 315 invasive clinical isolates of fluconazole-resistant Candida spp. J. Clin. Microbiol., 44, 324, 2006.

21. Morris M.I., Villmann M.: Echinocandins in the management of invasive fungal infections. Am. J. Health-Syst. Pharm., 63, 1693, 2006.

22. Nakai T. et al: In vitro antifungal activity of micafungin (FK463) against dimorphic fungi: comparison of yeast-like and mycelia forms. Antimicrob. Agents Chemother., 47, 1376, 2003. 
23. Nguyen K.T. et al.: Characterising the post-antifungal effects of micafungin against Candida albicans, Candida glabrata, Candida parapsilosis and Candida krusei isolates. Int. J. Antimicrob. Agents., $35,80,2010$.

24. Oliveira E.R. et al.: Antifungal susceptibility testing of micafungin against Candida glabrata isolates. Oral Surg. Oral Med. Oral Pathol. Oral Radiol. Endod., 105, 457, 2008.

25. Pappas P.G. et al.: Micafungin versus caspofungin for treatment of candidaemia and other forms of invasive candidiasis. Clin. Infect. Dis., 45, 883, 2007.

26. Pfaller M.A. et al.: Wild-type MIC distributions and epidemiological cut off values for the echinocandins and Candida spp. J. Clin. Microbiol., 48, 52, 2010.

27. Pfaller M.A. et al.: In vitro susceptibility of invasive isolates of Candida spp. to anidulafungin, caspofungin and micafungin: Six years of global surveillance. J. Clin. Microbiol., 46, 150, 2008.

28. Pfaller M.A. et al.: Global surveillance of in vitro activity of micafungin against Candida: A comparison with caspofungin by CLSI - recommended methods. J. Clin. Microbiol., 44, 3533, 2006.

29. Pfaller M.A. et al.: Correlation of MIC with outcome for Candida species tested against caspofungin, anidulafungin and micafungin: analysis and proposal for interpretive MIC breakpoints. J. Clin. Microbiol., 46, 2620, 2008.
30. Pfeiffer C.D. et al.: Breakthrough invasive candidiasis on micafungin. J. Clin. Microbiol., 48, 2373, 2010.

31. Prasad R., Kappor K.: Multidrug resistance in yeasts Candida. Int. Rev. Cytol., 242, 215, 2005.

32. Quindós G. et al.: In vitro antifungal activity of micafungin. Rev. Iberoam. Micol., 26, 35, 2009.

33. Quindós G., Villar-Vidal M., Eraso E.: Activity of micafungin against Candida biofilms. Rev. Iberoam. Micol., 26, 49, 2009.

34. Resende M.A. et al.: Prevalence and antifungal susceptibility of yeasts obtained from the oral cavity of elderly individuals. Mycopathologia, 162, 39, 2006.

35. Sucher A.J., Chahine E.B., Balcer H.E.: Echinocandins: The newest class of antifungals. Ann. Pharmacother., 43, 1647, 2009.

36. Temesgen Z., Barreto J., Vento S.: Micafungin - the newest echinocandin. Drugs Today, 45, 469, 2009.

37. Turner M.S., Drew R.H., Perfect J.R.: Emerging echinocandins for treatment of invasive fungal infections. Expert Opin. Emerg. Drugs., 11, 231, 2006.

38. White T.C. et al.: Resistance mechanisms in clinical isolates of Candida albicans. Antimicrob. Agents Chemother., 46, 1704, 2002. 